Research Article

\title{
Mixture Design Study of Fiber-Reinforced Self-Compacting Concrete for Prefabricated Street Light Post Structures
}

\author{
Wael Zatar ${ }^{1}$ and Tu Nguyen $\mathbb{D}^{2}$ \\ ${ }^{1}$ College of Engineering and Computer Sciences, Marshall University, Huntington, WV 25755, USA \\ ${ }^{2}$ Marshall University Research Corporation, Marshall University, Huntington, WV 25755, USA \\ Correspondence should be addressed to Tu Nguyen; nguyent@marshall.edu
}

Received 10 April 2020; Revised 18 May 2020; Accepted 26 May 2020; Published 15 June 2020

Academic Editor: Andreas Lampropoulos

Copyright ( $) 2020$ Wael Zatar and Tu Nguyen. This is an open access article distributed under the Creative Commons Attribution License, which permits unrestricted use, distribution, and reproduction in any medium, provided the original work is properly cited.

\begin{abstract}
In recent years, there has been an increasing demand to produce strong precast street light posts that are aesthetically pleasing. This study presents experimental results of a considerable number of mixture designs for fabricating precast street light posts where fiber-reinforced self-compacting concrete (FRSCC) was employed. The performance of many FRSCC mixtures was evaluated in terms of their structural properties and aesthetic characteristics. A trial-and-error procedure was performed for a series of FRSCC mixtures where silica fume, fly ash, and fibers were used. Slump flow and air content tests were conducted to determine the fresh FRSCC properties, and specimens were cast to evaluate their aesthetic. Three-day and seven-day compression tests were performed to examine the FRSCC hardened properties. The amount of cement in all batches was kept constant, whereas the distributions of fine and coarse aggregates, water, and other admixtures were adjusted. The largest slump flow of $73.7 \mathrm{~cm}$ (29 in) was recorded, and the maximum three-day compressive strength was $43 \mathrm{MPa}$ (6209 psi). Further refinement of the mixtures, which displayed the best strength and aesthetic attributes, was performed. Test results of the selected FRSCC mixtures indicated an excellent slump flow, air content, and compression values while achieving advantageous aesthetic qualities. Sevenday compressive strength of $39 \mathrm{MPa}(5686 \mathrm{psi})$ with the air content of 4.8 percent and the slump flow of $66 \mathrm{~cm}(26 \mathrm{in})$ was recorded. The study results and the developed FRSCC mixes can be used for mass production of precast concrete street light posts in precast plants.
\end{abstract}

\section{Introduction}

Precast concrete components for architectural applications often require a defect-free surface, colorful appearance, and high compressive strength. Self-compacting concrete (SCC) is an excellent candidate for such architectural expectations. White or colored concrete can be made with available white Portland cement, thus allowing the architectural design of artistic precast concrete elements without the need for additional painting materials. SCC is a highly flowable, nonsegregating concrete that can flow through tight reinforcement without mechanical consolidation [1]. The American Society for Testing and Materials (ASTM) standard defines SCC as "Concrete that can flow around reinforcement and consolidate under its own weight without additional effort and without exceeding specified limits of segregation" [2]. Since the early expansion of SCC in the 1980s in Japan [3-5], the use of SCC has grown tremendously for repair, on-site, and precast concrete applications internationally [6-11].

Fibers such as polypropylene, glass, and steel are typically added to the mixture to improve the cracking resistance ability of SCC under the effects of plastic and drying shrinkage. As per the finding in ACI 544.5R-10 report [12], the width of plastic shrinkage cracks reduced significantly with FRSCC using thin diameter fibers compared to that of FRSCC using thick fibers. The added fibers into the SCC mixture also reduced the permeability of FRSCC [13]. Researchers have investigated the effects of fibers on the mechanical properties of FRSCC. As an example, El-Dieb [14] investigated the effects of steel fibers on the ductility of FRSCC. Findings from the study revealed that the ductility 
of FRSCC significantly improved with the increasing amount of steel fiber in the mixture.

Unlike conventional concrete, a well-designed SCC mix must satisfy three functional requirements: filling ability, passing ability, and resistance to segregation [1]. To obtain the SCC design mix with those required properties, three basic mixture-proportioning approaches have been developed: (i) high powder content and high range water reducer admixture (HRWRA), (ii) low powder content with HRWRA and viscosity-modifying admixtures (VMAs), and (iii) moderate powder content with HRWRA and VMA dose [1]. The first practice uses a higher amount of cementitious materials, whereas the second approach utilizes VMA to control the fresh FRSCC properties. The last one is a combination of the two previous approaches.

One of the first SCC mixture design methods was proposed by Okamura and Ozawa [5]. The procedure in this method fixes the coarse aggregate and fine aggregate content and adjusts the amount of admixture as well as the water/ cement ratio to obtain the desired mix. American Concrete Institute (ACI) provided guidelines for SCC mixture design using an adapted version of Okamura and Ozawa's technique. The details of this method can be found in [1], and the necessary steps [15] were summarized as follows: (i) determine the appropriate slump flow requirements, (ii) select the appropriate maximum size coarse aggregate and coarse aggregate content, (iii) estimate the required cementitious/ powder content, (iv) calculate the paste and mortar volumes, (v) select the appropriate admixtures for use, (vi) batch trial mixtures, (vii) test the mixture for the required fresh and hardened properties, and (viii) adjust the proportions, rebatch, and test again.

Another significant method for SCC mixture design was developed by Su et al. [16]. This mix design method focused on filling the paste binders into voids of the aggregate. In other words, the proposed mix design method aimed to reduce the voids in the loose aggregate. By applying this method for SCC mix design, the passing ability of fresh SCC can be improved. In addition, the volume of sand to mortar also increased to the range of 54 to 60 percent, which was higher than that of Okamura and Ozawa's technique; therefore, it can be considered a cost-effective mix design method.

Regarding the mixture design of the FRSCC, intensive work has been implemented. For example, Khaloo et al. [17] studied two mixture designs with a strength of $40 \mathrm{MPa}$ and $60 \mathrm{MPa}$, respectively. The steel fiber volume of $0.5 \%, 1 \%, 1.5 \%$, and $2 \%$ was used. In another study, de la Rosa et al. [18] proposed a novel proportioning methodology for the mixed design of FRSCC with the fiber content up to $1 \%$ and the compressive strength between 30 and $80 \mathrm{MPa}$. A detailed description of a mix design method for FRSCC was also found in research conducted by Ferrara et al. [19].

It is worth noting that FRSCC is a special class of SCC, and FRSCC can be produced with various materials [20-22]. As a result, no definite mixture design can provide the optimum solution for all applications. It is necessary to modify the FRSCC formulation prior to every project. For this reason, an experimental work based on the procedure mentioned above [15] has been carried out to design an FRSCC mixture that can be used for fabricating precast concrete street light posts in the city of Huntington, WV. The project required designing and testing of FRSCC mixes that would provide a smooth appearance, defect-free surface, and high compressive strength to resist cracking.

Fiber-reinforced self-compacting concrete was selected for the construction of this project based on the requirement of the concrete to take the shape of the intricate details of the molds. It is essential to mention that conventional concrete mixes did not yield the elaborate artistic detail needed for this project. Since the aesthetic qualities are of such great importance in the beautification of the historic city of Huntington, high-performance concrete was necessary due to its workability without increasing water content or sacrificing strength.

\section{Experimental Setup}

2.1. Material Preparation. Cement and aggregate are two crucial ingredients for FRSCC mixtures. Cement used for this study was selected following ASTM C150 [23]. And to meet the architectural requirement, the same type of cement from an identical brand was used. The amount of cement was picked between 386 and $475 \mathrm{~kg} / \mathrm{m}^{3}$ (650 and $800 \mathrm{lb} . / \mathrm{yd}^{3}$ ) for precast components following ACI recommendations [1]. Aggregate was selected following ASTM C33 [24] with the maximum size of $1.25 \mathrm{~cm}(1 / 2 \mathrm{in})$. Other elements such as fly ash and silica fume were added to improve the workability, durability, and strength of FRSCC. Fly ash added to the FRSCC mix was in accordance with ASTM C618 [25]. As suggested by Florida DOT [26], the amount of fly ash ranged from 18 to 22 percent by mass of cement. Silica fume between seven and nine percent by mass of cement was used for the SSC mixtures to improve resistance to segregation and bleeding.

Superplasticizer was used in order to guarantee the FRSCC is flowable under its own mass. The use of HRWRA conforms to the requirements of ASTM C1017 [27]. Besides, VMA was added in the FRSCC mixtures as well to ensure the stability of fresh concrete. The amount of VMA was adjusted after each FRSCC batch to obtain the designed level of stability. In addition, air-entraining admixtures (AEAs) which met the requirements of ASTM C260 [28] were used for FRSCC mixtures to increase the resistance of the concrete to the freeze-thaw damage.

Polypropylene fibers ranging from 0.25 to 0.5 percent by volume were used to prevent concrete cracking due to plastic shrinkage. The application of this type of fiber in concrete has some advantages, such as no water demand and a high chemical attacked resistance. The properties of the fiber are presented in Table 1. Detailed information about the components for 14 selected FRSCC mixtures designed for a volume of $1 \mathrm{~m}^{3}$ is shown in Table 2 .

2.2. Mixture Procedure. A trial-and-error procedure was performed to obtain an optimal FRSCC mixture that meets the required properties. To make an FRSCC batch, the 
TABLE 1: Fiber properties.

\begin{tabular}{lccccc}
\hline Length $(\mathrm{mm})$ & Diameter $(\mathrm{mm})$ & Tensile strength $(\mathrm{MPa})$ & Modulus of elasticity $(\mathrm{GPa})$ & Specific surface $\left(\mathrm{m}^{2} / \mathrm{kg}\right)$ & Density $\left(\mathrm{kg} / \mathrm{cm}^{3}\right)$ \\
\hline $30-50$ & $0.30-0.35$ & $547-658$ & $3.50-7.50$ & 91 & 0.9 \\
\hline
\end{tabular}

TABLE 2: Material proportions for FRSCC mixtures.

\begin{tabular}{|c|c|c|c|c|c|c|c|c|c|c|}
\hline Batch & $\begin{array}{c}\text { Cement } \\
(\mathrm{kg})\end{array}$ & $\begin{array}{l}\text { Fly ash } \\
\text { (kg) }\end{array}$ & $\begin{array}{l}\text { Silica fume } \\
(\mathrm{kg})\end{array}$ & $\begin{array}{c}\text { Sand } \\
(\mathrm{kg})\end{array}$ & $\begin{array}{c}\text { Gravel } \\
(\mathrm{kg})\end{array}$ & $\begin{array}{l}\text { Fibers } \\
(\mathrm{kg})\end{array}$ & $\begin{array}{l}\text { Water } \\
(\mathrm{kg})\end{array}$ & $\begin{array}{l}\text { AEA } \\
(\mathrm{ml})\end{array}$ & $\begin{array}{l}\text { HRWRA } \\
(\mathrm{ml})\end{array}$ & $\begin{array}{l}\text { VMA } \\
(\mathrm{ml})\end{array}$ \\
\hline 1 & 448 & 119 & 28 & 761 & 791 & 2.98 & 215 & 62 & 3288 & 132 \\
\hline 2 & 448 & 119 & 28 & 719 & 749 & 2.98 & 185 & 78 & 3288 & 132 \\
\hline 3 & 448 & 119 & 28 & 683 & 813 & 2.98 & 215 & 105 & 4086 & 272 \\
\hline 4 & 448 & 119 & 28 & 683 & 813 & 2.98 & 215 & 93 & 4086 & 272 \\
\hline 5 & 448 & 119 & 28 & 683 & 813 & 2.98 & 179 & 93 & 4358 & 272 \\
\hline 6 & 448 & 91 & 57 & 689 & 813 & 2.98 & 197 & 78 & 4358 & 272 \\
\hline 7 & 448 & 119 & 28 & 683 & 813 & 2.98 & 197 & 47 & 4358 & 272 \\
\hline 8 & 448 & 119 & 28 & 683 & 813 & 2.98 & 197 & 156 & 4358 & 389 \\
\hline 9 & 448 & 119 & 28 & 683 & 813 & 2.98 & 197 & 93 & 4475 & 525 \\
\hline 10 & 448 & 119 & 28 & 683 & 813 & 2.98 & 197 & 93 & 4358 & 545 \\
\hline 11 & 448 & 119 & 28 & 683 & 813 & 2.98 & 197 & 93 & 4736 & 525 \\
\hline 12 & 448 & 119 & 28 & 683 & 813 & 2.98 & 215 & 93 & 4475 & 876 \\
\hline 13 & 448 & 119 & 28 & 683 & 813 & 2.98 & 215 & 93 & 4358 & 545 \\
\hline 14 & 448 & 119 & 28 & 683 & 813 & 2.98 & 209 & 93 & 4747 & 545 \\
\hline
\end{tabular}

ingredients were first weighed, and the air-entraining admixture was placed into the sand before mixing. The gravel and air-entrained sand were then added to the mixer. Threequarters of total water was added to saturate the aggregate and form slurry. The remaining water was divided into three portions, which were used for saturation of the three cementitious materials, namely, silica fume, cement, and fly ash.

The silica fume was added along with the first portion of the remaining water to the saturated aggregate. Once the silica fume was saturated and mixed into the slurry, the cement was added with the second portion of the remaining water. Then, the fly ash was added along with the remaining one-third of the water. At this point, all aggregates, cementitious materials, and water were in the mixer. The fibers were, then, added to the ingredients. Once the fibers were well distributed throughout the concrete, the superplasticizer (HRWRA) was added and left to mix for approximately five minutes. In the last step, the VMA was added and allowed to mix for five minutes before tests were performed. The mixing time in all batches was around 20 to 30 minutes.

2.3. Testing Objectives. The purpose of this study was to design an FRSCC mixture that can be used for mass fabrication of precast concrete street light posts. The mixture should provide a smooth appearance, no visual defect on the surface, and a high compressive strength. In order to meet these requirements, tests were performed for each batch of the FRSCC mixtures. The first series of fresh FRSCC tests were slump flow and air content tests. The second series of tests were the compression tests, which were conducted for FRSCC specimens after three days and seven days of curing. The expected 7-day compressive strength of concrete was in the range between 35 and $50 \mathrm{MPa}$ (5000 and $7200 \mathrm{psi}$ ). The target range for the slump flow of the fresh concrete was 51 to $64 \mathrm{~cm}$ (20 to $25 \mathrm{in}$ ), and the air content goals for the fresh FRSCC were from three to five percent.

2.4. Testing Procedure. To determine the filling ability of FRSCC, the slump flow test procedure, as presented in [29], was applied for each batch in this study. The test measures the relative flowability of the FRSCC mixture using an inverted slump flow cone. The slump flow cone was filled on a flat surface with no rodding or other consolidation methods and then lifted from the floor, allowing the concrete to flow outward. The diameter of the concrete was measured from various directions to obtain and the average value for the slump flow. Since the reinforcement configuration of the street light post structures was not tight, the passing ability (J-ring test) and the segregation resistance (V-funnel test) of the SCC mixtures were less critical. It should be pointed out that the J-ring and V-funnel tests are critical in all situations where there is crowding of reinforcing bars (such as connection areas).

Another crucial property of fresh FRSCC is the air entrainment, which is essential since the concrete will be directly exposed to freeze-thaw cycles throughout its lifetime. Air content tests were performed for fresh concrete to make sure concrete can resist the frost-related damage. In this study, the pressure method [30] was used to measure the air content in the fresh FRSCC due to its relative speed compared to other methods.

To determine the mechanical properties of materials, different methods can be used [31-34]. In this study, compression tests were performed using standard cylinder specimens of $150 \mathrm{~mm}$ in diameter and $300 \mathrm{~mm}$ in height $(6 \times 12$ in $)$ to determine the compressive strength of FRSCC. For each FRSCC batch, a set of three specimens was made by filling the cylinders without rodding. After removing from 
the mold, the specimens were cured in water until the compression tests were carried out. The traditional compression testing procedures [35] were followed to obtain the three-day and seven-day compressive strength of the FRSCC mixtures.

\section{Results and Discussion}

3.1. Mixture Adoption. As can be seen in Table 2, for the first batch, the mix employed $62 \mathrm{ml}(2.09 \mathrm{oz})$ of AEA, 3.291 $(112 \mathrm{oz})$ of HRWRA, and $132 \mathrm{ml}(4.46 \mathrm{oz})$ of VMA. The amount of gravel was set to 54 percent of the total aggregate to facilitate a high compressive strength. The water/cement ratio was 0.36 to achieve complete hydration while reducing the water content enough to gain adequate strength. Batch 1 exhibited acceptable slump flow, air content, and compressive strength for the needs of this project.

In batch 2, the AEA was increased from $62 \mathrm{ml}(2.09 \mathrm{oz})$ to $78 \mathrm{ml}(2.63 \mathrm{oz})$, the water was reduced from $215 \mathrm{~kg}$ (473 lbs.) to $185 \mathrm{~kg}$ (407 lbs.) to gain more strength, and $42 \mathrm{~kg}$ (92 lbs.) of both sand and gravel was excluded from the mix. The rest of the mix proportions remained unchanged from batch 1. Batch 2 exhibited a slump flow reduction of $8.89 \mathrm{~cm}(3.5 \mathrm{in})$ to $50.8 \mathrm{~cm}(20 \mathrm{in})$ in total. The air content was lower than that of batch 1 with an additional $16 \mathrm{ml}$ $(0.57 \mathrm{oz})$ of AEA, which may have been a result of a quicker mix time than batch 1 . The reduction of water resulted in a decreased slump flow without affecting the compressive strength.

It is worth noting that the performance of the FRSCC mixture in batch 5 was close to ideal with a slump flow of $58.4 \mathrm{~cm}$ (23 in) and an amount of air content of six percent. The compressive strength was the strongest of all the mixes tested. This mix exhibited the worst aesthetic features of all the mixes. This downside was improved, and the desired mixture was achieved in batch 14. By taking advantage of the previous batches, the water in batch 14 was reduced from $215 \mathrm{~kg}$ (473 lbs.) to $209 \mathrm{~kg}$ (460 lbs.) to improve strength. The superplasticizer was increased from $4.36 \mathrm{l}(147 \mathrm{oz})$ to $4.75 \mathrm{l}$ $(160 \mathrm{oz})$ to achieve a larger diameter slump flow and increased workability. The test results from this batch showed a good slump flow, air content, and compression values with an acceptable aesthetic.

3.2. Slump Flow and Air Content. Table 3 presents the experimental results from the slump flow test. The range of slump flow from the majority batches fell between $50 \mathrm{~cm}$ (20 in) and $70 \mathrm{~cm}(28 \mathrm{in})$, which was in line with the recommendation of Nagataki and Fujiwara [36] for high flowable concrete. The slump flow varied significantly from batch to batch. The record low of slump flow was $50.8 \mathrm{~cm}$ (20 in) for concrete in batch 2 . The reason for this low value might be due to the reduction of water in the mixture while other ingredients remained constant. The maximum slump flow of $73.7 \mathrm{~cm}$ (28.7 in) was found in batch 12 . An increase in the amount of VMA from $525 \mathrm{ml}$ (previous batch) to $876 \mathrm{ml}$ while keeping other components the same would be a cause for an increase of slump flow in batch 12 .
TABLE 3: Slump flow and air content test results.

\begin{tabular}{lcc}
\hline Batch & Slump flow $(\mathrm{cm})$ & Air content $(\%)$ \\
\hline 1 & 59.7 & 5.5 \\
2 & 50.8 & 3.5 \\
3 & 63.5 & 6.2 \\
4 & 63.7 & 2.4 \\
5 & 58.4 & 6.0 \\
6 & 55.9 & 5.0 \\
7 & 63.5 & 4.2 \\
8 & 63.5 & 4.4 \\
9 & 66.0 & 4.4 \\
10 & 63.5 & 5.5 \\
11 & 63.5 & 4.0 \\
12 & 73.7 & 4.4 \\
13 & 63.5 & 3.9 \\
14 & 66.0 & 4.8 \\
\hline
\end{tabular}

With respect to the air content test, the experimental results are presented in Table 3. As can be seen from the table, the air content of the concrete mixtures varied within $5 \pm 2$ percent. The wide range of air content might be due to a large amount of HRWRA used in the SCC mixtures. The air content of SCC mixtures in this study, however, stayed within the expected ranges. It is worth noting that the maximum air content of 6.2 percent was found in batch 3 . The number was reasonable compared to the results found in the previous study [37]. The experimental results from the selected batch 14 showed an excellent slump flow of $66 \mathrm{~cm}$ (26 in) with an air content of 4.8 percent.

3.3. Compressive Strength. Besides the slump flow and air content tests, the compression tests were carried out for the test samples to obtain the three-day and seven-day compressive strengths of FRSCC. Table 4 presents the compression test results of concrete test samples from selected batches at day three and seven days. In some batches, due to the failure in conducting the compressive strength at seven days, these results were not reported in the table. The compressive strengths of specimens varied between 33.1 to $43.2 \mathrm{MPa}$ (4800 to $6265 \mathrm{psi}$ ) and 36.4 to $51.5 \mathrm{MPa}$ (5279 to $7470 \mathrm{psi}$ ) for three days and seven days, respectively, which fell in the expected ranges.

The average three-day compressive strength of batch 3 was lower than that of the previous batch, at $35.8 \mathrm{MPa}$ (5332 psi), compared to $39 \mathrm{MPa}$ (5658 psi) for batch 2 . The reduction in the three-day compressive strength of cylinders in batch 3 is due to the increase of water and the coarse aggregate adjustments. The FRSCC strength of a three-day compression test results of batch 5 yielded the highest strength of all the mixed tests so far, $43.2 \mathrm{MPa}$ (6265 psi). Several trials were conducted after this point, and the desired mix was attained in batch 14 with the seven-day compressive strength of FRSCC of $39.2 \mathrm{MPa}$ (5686 psi).

Figure 1 shows the compression failure of selection cylinders from four batches. As can be seen in Figure 1(a), the cylinder broke along the edge, not through the center. It is believed that this was caused by cylinder molds that were 
TABLE 4: Compressive strength test results.

\begin{tabular}{lcc}
\hline Batch & \multicolumn{2}{c}{$\begin{array}{c}\text { The average strength of FRSC (MPa) } \\
\text { Seven-day compressive strength }\end{array}$} \\
\hline 1 & Three-day & 51.5 \\
2 & 33.1 & 48.7 \\
3 & 39.0 & 49.8 \\
4 & 35.8 & - \\
5 & 30.8 & - \\
6 & 43.2 & - \\
7 & 36.7 & 49.0 \\
8 & 29.3 & 50.7 \\
9 & 31.0 & 36.4 \\
10 & 27.6 & 38.6 \\
11 & 30.5 & 47.8 \\
12 & 38.9 & 42.4 \\
13 & 28.9 & 48.2 \\
\hline
\end{tabular}

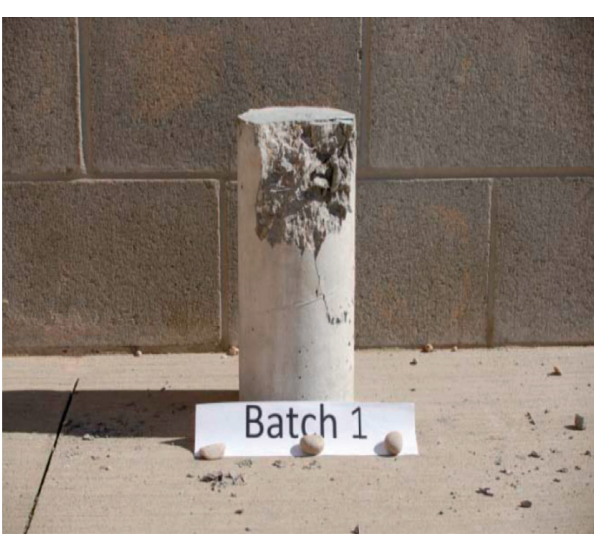

(a)

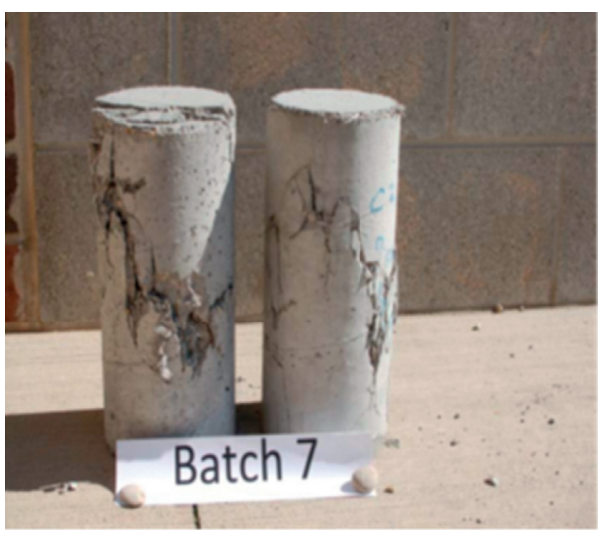

(c)

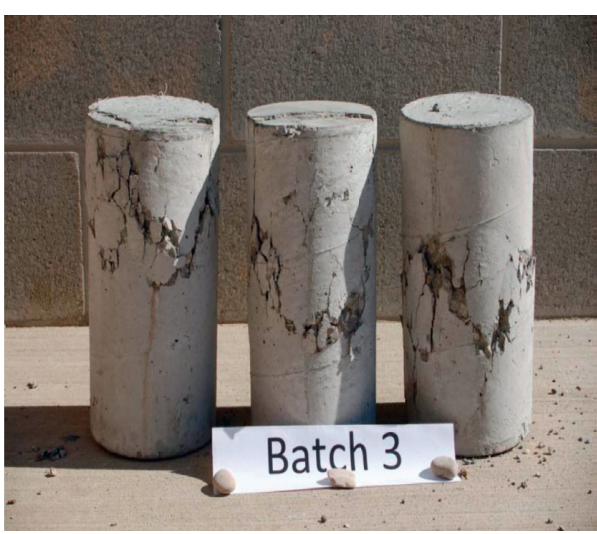

(b)

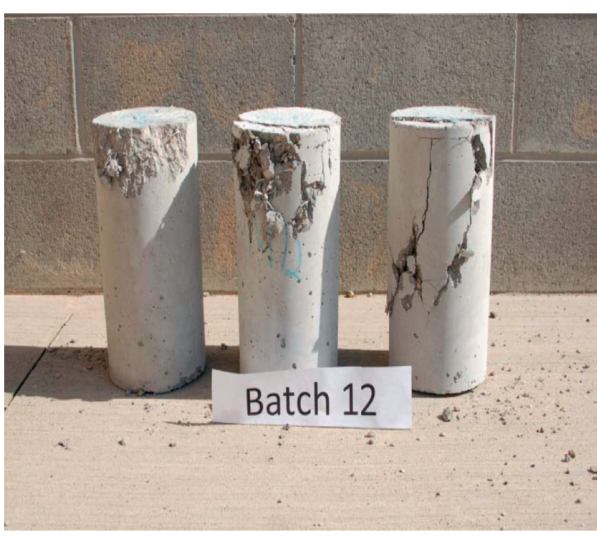

(d)

Figure 1: Compression failure of specimens from four batches. (a) Batch 1. (b) Batch 3. (c) Batch 7. (d) Batch 12.

not perfectly flat on the bottom. The effects of the molds on compressive strength were improved in the subsequent batches, as seen in Figure 1(b). The failure shapes of concrete specimens from batch 3 were better than that of batch 1 and batch 2 .
3.4. Aesthetic Characteristics. As mentioned above, a great aesthetic quality was one of the requirements for the desired FRSCC mixtures. Therefore, in each FRSCC batch, several samples were cast to evaluate the aesthetic characteristics of the FRSCC. Figure 2 shows the impression results from 


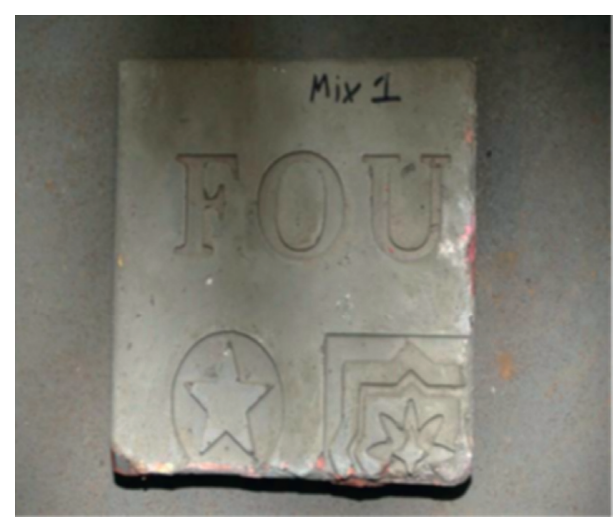

(a)

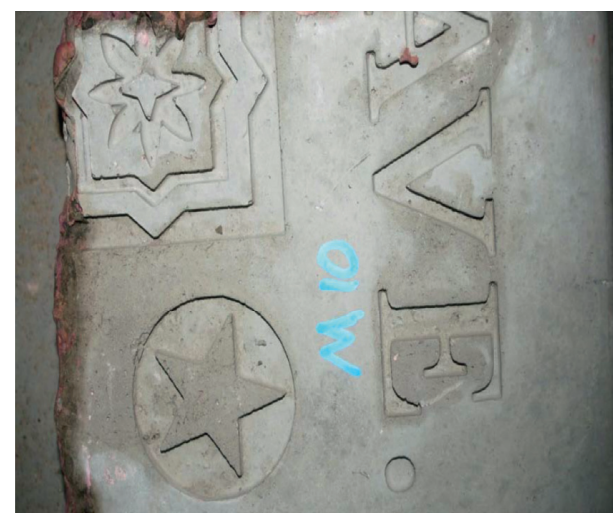

(c)

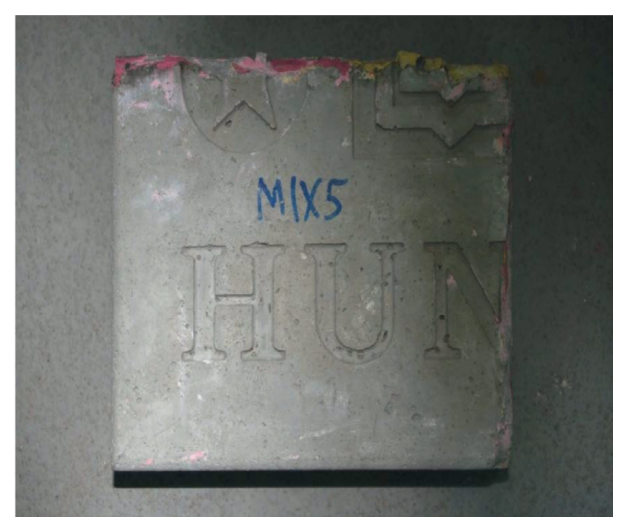

(b)

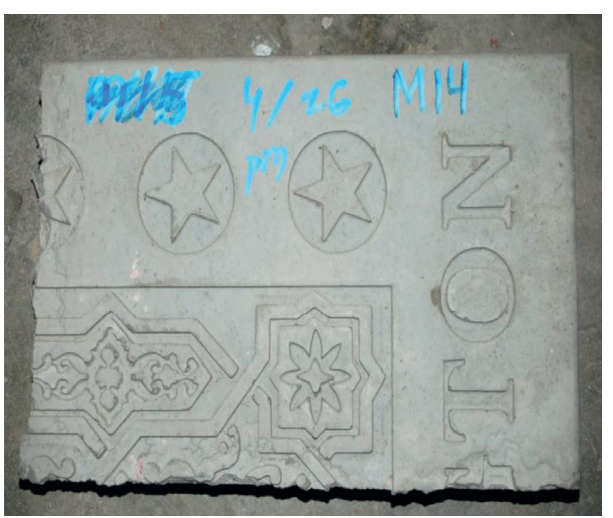

(d)

Figure 2: Impression result of samples from different batches. (a) Batch 1. (b) Batch 5. (c) Batch 10. (d) Batch 14.

selected batches. Overall, the color variation from a specimen to another was negligible. The specimens were easily removed from the folds, but the quality of the artworks in terms of sharpness and details varied significantly among specimens.

As can be seen in the specimen sample from batch 1 , Figure 2(a), the artwork appearance formed very well, but some minor surface voids were still present. The quality of the artwork improved significantly after several trials. Only very slight air voids on the surface of artwork from batch 6 were observed, as shown in Figure 2(b). Excellent results were obtained in the specimens made from the mix in batch 10 . As presented in Figure 2(c), the artwork had almost no surface voids and a smooth finish. Figure 2(d) shows the aesthetic results of the sample from the selected batch. The sample looked perfect with a smooth finish and virtually no surface voids.

\section{Conclusions}

Experimental results from a comprehensive number of FRSCC mix designs were presented. A trial-and-error procedure that aimed at yielding desirable results was adopted. The fresh concrete properties, such as filling ability and air content, were evaluated. In addition, the hardened properties and aesthetic features of the design mix were examined. The study concluded that appropriate mix designs met all desired properties and aesthetics. The 7-day compressive strength of FRSCC fell within the desired range of 35 to $50 \mathrm{MPa}$ (5000 to $7200 \mathrm{psi}$ ), and the 4.8 percent of air content required for the concrete was achieved. Finally, this study suggests that the mix in batch 14 be implemented for mass production of precast concrete street light posts.

\section{Data Availability}

The data used to support the findings of this study are included in the article.

\section{Conflicts of Interest}

The authors hereby declare no potential conflicts of interest with respect to the research, authorship, and/or publication of this article.

\section{Acknowledgments}

This work was supported by the West Virginia Department of Transportation (WVDOT) through the research project entitled "Corrosion Research to Maintain and Sustain Infrastructure in West Virginia."

\section{References}

[1] ACI 237R-07, "Emerging technology series self-compacting concrete reported," ACI Committee, vol. 237, 2007. 
[2] ASTM C125-19, Standard Terminology Relating to Concrete and Concrete Aggregates, ASTM International, West Conshohocken, PA, USA, 2019.

[3] K. Tanaka, K. Sato, S. Wanatabe, and K. Suenaga, "Development and utilization of high performance concrete for the construction of the Akashi Kaikyo bridge," High Performance Concrete in Severe Environment, vol. 140, pp. 25-52, 1993.

[4] N. Miura, N. Takeda, R. Chikamatsu, and S. Sogo, "Application of super workable concrete to reinforced concrete structures with difficult construction conditions," High Performance Concrete in Severe Environment, vol. 140, pp. 163186, 1998.

[5] H. Okamura and K. Osawa, "Mix design for self-compacting concrete," Concrete Library of JSCE, vol. 1, Article ID 107e120, 1995.

[6] K. H. Khayat and D. Feys, "Design, production and placement of self-compacting concrete," RILEM Book Series, Springer, London, UK, 2010.

[7] M. R. Geiker, "Self-compacting concrete (SCC)," in Developments in the Formulation and Reinforcement of Concrete, British Welding Research Association, Cambridge, UK, 2008.

[8] J. Silfwerbrand, "Bonded concrete overlays for repairing concrete structures," in Failure, Distress and Repair of Concrete Structures, Woodhead Publishing, Cambridge, UK, 2009.

[9] H. K. Khayat and P.-C. Aitcin, "Use of self-consolidating concrete in Canada-present situation and perspectives," in Proceedings of the International Workshop on Self-Compacting Concrete, Kochi University of Technology, Kochi, Japan, pp. 11-22, August 1998.

[10] P. L. Domone, "Self-compacting concrete: an analysis of 11 years of case studies," Cement and Concrete Composites, vol. 28, no. 2, pp. 197-208, 2006.

[11] M. Ouchi, S. Aki Nakamura, M. Lwin, and S. Erik, "Applications of self-compacting concrete in Japan, Europe and the United States," ISHPC, vol. 1, pp. 1-20, 2003.

[12] ACI 544.5R-10, Report on the Physical Properties, and Durability of Fiber-Reinforced Concrete, ACI Committee, Farmington Hills, MI, USA, 2010.

[13] L. Vandewalle, "Test and design methods for steel fiber reinforced concrete-final recommendation," Materials and Structure, vol. 35, no. 253, 2002.

[14] A. S. El-Dieb, "Mechanical, durability and microstructural characteristics of ultra-high-strength self-compacting concrete incorporating steel fibers," Materials \& Design, vol. 30, no. 10, pp. 4286-4292, 2009.

[15] J. Daczko, Self-Consolidating Concrete, CRC Press, Baco Raton, FL, USA, 2012.

[16] N. Su, K.-C. Hsu, and H.-W. Chai, "A simple mix design method for self-compacting concrete," Cement and Concrete Research, vol. 31, no. 12, pp. 1799-1807, 2001.

[17] A. Khaloo, E. M. Raisi, P. Hosseini, and H. Tahsiri, "Mechanical performance of self-compacting concrete reinforced with steel fibers," Construction and Building Materials, vol. 51, pp. 179-186, 2014.

[18] Á. de la Rosa, E. Poveda, G. Ruiz, and H. Cifuentes, "Proportioning of self-compacting steel-fiber reinforced concrete mixes based on target plastic viscosity and compressive strength: mix-design procedure \& experimental validation," Construction and Building Materials, vol. 189, pp. 409-419, 2018.

[19] L. Ferrara, Y.-D. Park, and S. P. Shah, "A method for mixdesign of fiber-reinforced self-compacting concrete," Cement and Concrete Research, vol. 37, no. 6, pp. 957-971, 2007.
[20] M. A. S. Anjos, A. Camões, P. Campos, G. A. Azeredo, and R. L. S. Ferreira, "Effect of high-volume fly ash and metakaolin with and without hydrated lime on the properties of self-compacting concrete," Journal of Building Engineering, vol. 27, Article ID 100985, 2020.

[21] A. I. Al-Hadithi and N. N. Hilal, "The possibility of enhancing some properties of self-compacting concrete by adding waste plastic fibers," Journal of Building Engineering, vol. 8, pp. 20-28, 2016.

[22] R. H. Faraj, A. F. H. Sherwani, and A. Daraei, "Mechanical, fracture and durability properties of self-compacting high strength concrete containing recycled polypropylene plastic particles," Journal of Building Engineering, vol. 25, Article ID 100808, 2019.

[23] ASTM C150/C150M-18, Standard Specification for Portland Cement, ASTM International, West Conshohocken, PA, USA, 2018.

[24] ASTM C33/C33M-18, Standard Specification for Concrete Aggregates, ASTM International, West Conshohocken, PA, USA, 2018.

[25] ASTM C618-19, Standard Specification for Coal Fly Ash and Raw or Calcined Natural Pozzolan for Use in Concrete, ASTM International, West Conshohocken, PA, USA, 2019.

[26] D.O.T. Florida, Standard Specifications for Road and Bridge Construction, Florida D.O.T, Tampa, FL, USA, 2004.

[27] ASTM C1017/C1017M-13e1, Standard Specification for Chemical Admixtures for Use in Producing Flowing Concrete, ASTM International, West Conshohocken, PA, USA, 2013.

[28] ASTM C260/C260M-10a, Standard Specification for AirEntraining Admixtures for Concrete, ASTM International, West Conshohocken, PA, USA, 2016.

[29] ASTM C1611/C1611M-18, Standard Test Method for Slump Flow of Self-Consolidating Concrete, ASTM International, West Conshohocken, PA, USA, 2018.

[30] ASTM C231/C231M-17a, Standard Test Method for Air Content of Freshly Mixed Concrete by the Pressure Method, ASTM International, West Conshohocken, PA, USA, 2017.

[31] T. T. Nguyen, T. N. Dao, S. Aaleti, K. Hossain, and K. J. Fridley, "Numerical model for creep behavior of axially loaded CLT panels," Journal of Structural Engineering, vol. 145, Article ID 04018224, 2019.

[32] A. Abdelmawla and S. S. Kim, "Application of ground penetrating radar to estimate subgrade soil density," Infrastructures, vol. 5, no. 2, p. 12, 2020.

[33] T. T. Nguyen and K. Dinh, "An artificial intelligence approach for concrete hardened property estimation," Journal of Science and Technology in Civil Engineering (STCE) -NUCE, vol. 14, no. 2, pp. 40-52, 2020.

[34] T. T. Nguyen, "Modeling of CLT creep behavior and real-time hybrid simulation of a CLT-LiFS building," Doctoral dissertation, University of Alabama, Tuscaloosa, AL, USA, 2017.

[35] ASTM C873/C873M-15, Standard Test Method for Compressive Strength of Concrete Cylinders Cast in Place in Cylindrical Molds, ASTM International, West Conshohocken, PA, USA, 2015.

[36] S. Nagataki and H. Fujiwara, "Self-compacting property of highly-flowable concrete," ACI Special Publication, vol. 154, pp. 301-314, 1995.

[37] M. Barfield and N. Ghafoori, "Air-entrained self-consolidating concrete: a study of admixture sources," Construction and Building Materials, vol. 26, no. 1, pp. 490-496, 2012. 